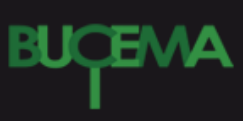

Bulletin du centre d'études médiévales d'Auxerre | BUCEMA

Hors-série $n^{\circ} 7 \mid 2013$

Les nouveaux horizons de l'ecclésiologie : du discours clérical à la science du social

\title{
Note liminaire : L'ecclésiologie et son histoire
}

\section{(2) OpenEdition}

Journals

Édition électronique

URL : https://journals.openedition.org/cem/12857

DOI : $10.4000 /$ cem. 12857

ISSN : 1954-3093

Éditeur

Centre d'études médiévales Saint-Germain d'Auxerre

Référence électronique

« Note liminaire : L'ecclésiologie et son histoire », Bulletin du centre d'études médiévales d'Auxerre I

BUCEMA [En ligne], Hors-série n 7 | 2013, mis en ligne le 29 mars 2013, consulté le 04 mars 2023

URL : http://journals.openedition.org/cem/12857 ; DOI : https://doi.org/10.4000/cem.12857

Ce document a été généré automatiquement le 4 mars 2023.

\section{(9) $\odot \Theta(\odot)$}

Creative Commons - Attribution - Pas d'Utilisation Commerciale - Partage dans les Mêmes Conditions 4.0 International - CC BY-NC-SA 4.0

https://creativecommons.org/licenses/by-nc-sa/4.0/ 


\section{Note liminaire : L'ecclésiologie et son histoire}

1 Encore très récemment, l'ecclésiologie était perçue comme une expression confessionnelle militante. Il est vrai que ses usages intra-ecclésiaux renvoient automatiquement à l'œcuménisme et à des perspectives fort éloignées de celles de cette collection d'essais (voir par exemple Brad Harper et Paul Louis Metzger, Exploring Ecclesiology, Grand Rapids, 2009). Un autre facteur, cette fois-ci académique, explique la méfiance envers le terme "ecclésiologie ", ou généralement son inexistence dans la sphère scientifique : outre la laïcité académique, l'« histoire religieuse » s'est souvent concentrée sur les pratiques, polarisant son regard sur les clercs porteurs de l'institution, plus que sur l'histoire des textes théoriques. À cette aune, Quentin Skinner, un historien qui s'est penché sur l'histoire des théories politiques, est souvent perçu, en France, comme «idéaliste ». En outre, l'histoire religieuse a aussi souvent délaissé l'étude des corpus normatifs à l'histoire du droit, dont chacun sait que la place se réduit, en tout cas en France, à une peau de chagrin, surtout en ce qui concerne l'étude des droits savants. Ainsi, l'étude des textes théoriques, qui est décisive pour l'ecclésiologie comme discours des clercs sur le social, est loin d'être "prioritaire" dans le programme des chercheurs en sciences sociales - «prioritaire » étant employé ici en forme de litote. En sens inverse mais de façon tout autant peu productive, a joué la reconsidération des thématiques "théologico-politiques » de la part de penseurs totalement hostiles, pendant les années 1960-1990, à tout ce qui de près ou de loin touchait le religieux. D'où, dans le milieu universitaire, une modification des impératifs - jadis trop suspicieux et crispés - de la laïcité, qui permet de donner à l'« objet » ecclésiologie une place légitime, mais largement biaisée, dans le champ scientifique.

2 Par ailleurs, du côté des universités confessionnelles, le modèle dominant semble plutôt celui d'une « whig theology " (pourrait-on dire en détournant Herbert Butterfield) qui utilise les textes anciens en fonction de problèmes contemporains. S'il n'est pas ici question de condamner cette pratique, qui suit la facture réelle de l'immense majorité du corpus de la tradition, ce n'est pas l'approche que nous avons choisie, même si ce qui a motivé la première rencontre à l'origine de cette partie sur l'historiographie de l'ecclésiologie est tout simplement le poids certain d'une figure particulière pour le 
domaine: celle d'Yves Congar, dont l'œuvre décisive, entre écrits scientifiques et articles d'actualité, témoigne encore, et de manière exemplaire, du lien entre histoire, historiographie et engagement confessionnel. C'est donc tout naturellement qu'il nous a paru nécessaire de ne pas nous limiter à cette perspective, d'interroger sa position, et de la faire jouer avec d'autres auteurs, d'autres champs, fussent-ils apparemment périphériques.

3 Peu à peu s'est d'ailleurs imposée comme une évidence la nécessité de faire l'histoire (réflexive) de la constitution de l'ecclésiologie. Quand nous parlons d'ecclésiologie, d'où venons-nous, où en sommes-nous, et où allons-nous? Ainsi ces premiers chapitres annoncent-ils un volume autonome consacré à l'historiographie de l'ecclésiologie, du $\mathrm{XVIII}^{\mathrm{e}} \mathrm{au} \mathrm{Xx}^{\mathrm{e}}$ siècle. Il s'agira à la fois d'examiner la manière dont l'ecclésiologie s'est constituée en discipline, avec quels outils, selon quelle temporalité et quels effets, mais aussi de prendre conscience de manière historicisée et réflexive des catégories qui se sont comme naturellement imposées à ceux qui entrent dans ce champ. Enfin, l'identification de nœuds historiques prégnants permettra de relire l'histoire de cette période du point de vue de l'ecclésiologie. 